\title{
ARGENTINA: CUESTIÓN MILITAR Y DISCURSO JURÍDICO DEL OLVIDO
}

Sumario:

I) Condicionamiento de la vida política argentina; II) Construcción de un discurso jurídico específico; III) La estrategia oficial y el protagonismo de los jueces; IV) La ideología «del olvido» y las concesiones al poder militar: A) la ley de «punto final», B) la ley de obediencia debida. Conclusión.

\section{I}

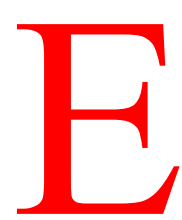

1 tratamiento de la cuestión militar en Argentina ha sido permanentemente uno de los motivos más importantes que ha condicionado la vida política del país. Observados todos ellos en conjunto -presencias de la oligarquía, intervención del imperialismo, participación de la jerarquía eclesiástica, etc.- éste es el que más ha marcado el tipo de relaciones entre el Estado y la sociedad civil argentina. Así ha ocurrido por lo menos desde 1930, año en que se produjo la primera interrupción de la legalidad democrática -el 6 de septiembre- a consecuencia del golpe militar de corte fascista encabezado por el Gral. José E. Uriburu.

La historia posterior de esas relaciones ha estado intermitentemente viciada por los desequilibrios causados entre regímenes de facto, de origen castrense, y gobiernos constitucionales más o menos democráticos. La verificación objetiva de semejante cuadro histórico no ha hecho más que afirmar una hipótesis de investigación en filosofía política que ha provocado un análisis variado de esa realidad. Ello así, pues el carácter reiterativo de las intervenciones políticas de las Fuerzas Armadas (FF. AA.), principalmente del Ejército, y la estabilidad de la hegemonía militar como «esquema de poder» en el marco de un Estado donde esos fenómenos constituyen el eje de la vida política desde hace casi sesenta anos, no puede ser menos que rico manantial para distintas perspectivas disciplinarias (cfr. Rouquié, 1983, 20).

Pero al promediar los años setenta y después de un esbozo llevado a cabo con el régimen militar encabezado en primer término por el Gral. Juan C. Onganía (la llamada «Revolución Argentina», iniciada el 28 de junio de 1968), se puso en ejecución el proyecto hegemónico neo-liberal que apoyaba sobre dos aspectos esenciales, cuales fueron: el favorecimiento del ingreso en el país del capital oligopólico internacional y la conocida «doctrina de la seguridad nacional» (cfr. Bergalli 1981), mediante la que toda la disidencia ideológica y la resistencia popular contra el primer aspecto pudo ser materialmente destruida. El aniquilamiento de quienes se opusieron a semejante proyecto que arrastró miles de víctimas 
a la tortura, a la muerte, a la desaparición y al exilio, reveló una crueldad inusitada en la historia nacional y puso de manifiesto hasta qué punto existió una total compenetración en todos los niveles de las tres FF. AA. para la ejecución de tan siniestro plan.

Es por todo lo dicho que -después de las múltiples, comprobadas y gravísimas violaciones de los derechos humanos en que incurrieron las FF. AA. en general, las denominadas como de seguridad y las policiales durante la década que ya puede llevar el adjetivo de «bárbara» (1974-1983)- el problema de las responsabilidades militares ha sido uno que ha venido condicionando hasta la propia forma de la democracia instaurada a partir del 10 de diciembre de 1983, fecha de la asunción del gobierno constitucional presidido por Raúl Alfosín.

Es verdad que desde su precedente campaña política el propio Alfonsín anunció y proclamó que las responsabilidades de quienes incurrieron en aquellas graves violaciones serían consideradas según tres niveles diferentes; el de los que impartieron las órdenes, el de los que las cumplieron dentro del mandato y el de los que las ejecutaron pero excediéndose. Este aspecto, junto al objetivo de analizar esas responsabilidades en el marco del ordenamiento jurídico, utilizando la legislación penal preexistente, supuso la substancia del mensaje ético para la futura acción de gobierno lo que seguramente fue el rasgo que cautivó el voto de los argentinos en aquella histórica elección del 30 de octubre de 1983.

Diríase que la inmensa mayoría de los argentinos quedó luego satisfecha cuando se dieron los primeros pasos en relación a dirimir aquellas responsabilidades en la década bárbara. El procesamiento de los cabecillas de un sector importante del movimiento guerrillero (Decreto 157 del Poder Ejecutivo, de 13 de diciembre 1983) y el de los Comandantes Generales que integraron las tres primeras Juntas Militares como órganos de gobierno en el régimen de facto a partir del 24 de marzo de 1976 -se excluyó a los miembros de la cuarta Junta bajo el argumento de que para la época en que ésta se constituyó ya no tenían prácticamente vigencia las operaciones basadas en métodos y procedimientos ilegales(Decreto 158 de la misma fecha), constituyó el primer paso de la estrategia oficial de la democracia para encarar la cuestión militar dentro del marco del Estado de derecho y quizá, en un primer momento, fue lo que generó la satisfacción aludida. Sin embargo, posiblemente por extrema aplicación de esa forma-Estado o por timidez política ante la histórica ocasión, o en definitiva, porque el propio consenso -incluso dentro del mismo Partido Radical- así lo exigía, aquella estrategia adoptó un sesgo que de inmediato se reveló como erróneo o, al menos, francamente endeble frente al poder militar.

Se abre así un período en el que comienzan a constatarse dos circunstancias que son las que aquí quiero destacar como componentes esenciales del derecho y la justicia de este proceso en Argentina de transición 
hacia la democracia. Una, es la relativa a la construcción de una forma particular de discurso jurídico -en el sentido foucaultiano de producción controlada, seleccionada y redistribuida del discurso mediante el juego de distintas prohibiciones y su vinculación con ciertas regiones del poder, como la de la política (cfr. Foucault 1983, 12)- en la que la creación teórica del derecho (penal) y su aplicación específica, revelan una peculiaridad propia al momento histórico de la formación social argentina. Este momento, que se presenta visiblemente condicionado por la cuestión militar, no es sino el punto en el que se expresan históricamente los conflictos, los acuerdos y las tensiones de los grupos sociales que hoy actúan con cierta incidencia en la Argentina contemporánea.

La otra circunstancia que deseo destacar se traduce en una inocultable voluntad de ese discurso jurídico que, aunque formalmente elaborado para la represión o el castigo de los torturadores, asesinos o «desaparecedores» militares, parece más bien orientada a cancelar de la memoria histórica de los argentinos lo acaecido en materia de violaciones a los derechos humanos. Este constituye un perfil importante pero escasamente analizado entre los componentes que integran los procesos de creación y aplicación del derecho. Se trata, ciertamente, de aquel aspecto de la cultura de un pueblo que lo señala con características particulares y que, finalmente, lo identifica como tal a través de la historia. Es, en efecto, la memoria colectiva aquel rasgo cultural mediante el cual es posible individualizar la voluntad y los deseos de una sociedad para perpetuarse como tal (cfr. Durkheim 1982, 94). Se sabe, asimismo, que en Durkheim la solidaridad -la cohesión social- a que da lugar el encuentro de las creencias y de los sentimientos, es de tipo mecánico de modo tal que la conciencia colectiva es el contenido moral de esa solidaridad y el derecho penal es su forma, su expresión, su signo viviente; es, por lo tanto, el producto del núcleo central de semejante conciencia, de los sentimientos más penetrantes y precisos de la sociedad que da lugar a la aparición de un instrumento de control social tan duro y eficaz como el sistema penal. A partir entonces de señalar la mayor o menor presencia de memoria; es decir, de reconocer la voluntad de una determinada formación social por recordar su propio pasado, sancionando como delitos y castigando con penas aquellas creencias y sentimientos (para el caso, los derechos humanos fundamentales), puede entenderse hasta qué punto el ordenamiento jurídico recoge -o no- esas expresiones en un momento determinado de constitución de la forma-Estado y qué papel desempeñan en el ius-dicere aquellos encargados de aplicar e interpretar el derecho.

Lo que acabo de señalar podrá verificarse mediante el análisis de la legislación creada en Argentina en época democrática para encarar las responsabilidades de las fuerzas militares, policiales y de seguridad o a través de la observación del comportamiento que ha revelado un sector importante de la clase judicial. A la luz de este cotejo cabe preguntarse si aquí la supuesta represión o castigo de las violaciones a los derechos humanos en la década bárbara no ha funcionado como una forma que tiende a encubrir y ocultar la producción de ideología jurídica, contrariamente a lo que habitualmente se cree que es función de la ideología: 
disfrazar el ejercicio de la represión, tal como ocurre en el plano de las costumbres, de la educación, de los medios de comunicación de masas que al configurar prácticas materiales expresan la existencia material de la ideología y asumen la forma general de prácticas jurídicas (así Entelman 1982, 13-14). Pienso que el caso particular de creación de un discurso jurídico oficial tan peculiar, como el que se ha producido en Argentina, ha estado dirigido precisamente a lo contrario, o sea a preparar una ideología jurídica «del olvido».

\section{III}

Un aspecto previo a la concreción de la estrategia oficial respecto a la cuestión militar que sin embargo revela desde un principio lo erróneo o lo débil de ella, cara al futuro, lo constituyó la decisión política del gobierno democrático de proceder a la convalidación de un elevado porcentaje de los jueces y fiscales que, habiendo actuado o siendo nombrados como tales durante el período de la dictadura militar -por lo tanto, en régimen de facto y en consecuencia al margen del sistema previsto por la Constitución Nacional (art. 86, inc. 5..$^{\circ}$ C.N.)- nunca cuestionaron ni promovieron acciones que permitieran investigar en aquella época las actividades represivas llevadas a cabo por las FF. AA. En muchos casos -y precisamente en los de aquellos magistrados judiciales que luego tuvieron que decidir sobre las responsabilidades militares más graves en sede de la Justicia Federal- el Poder Ejecutivo, con el respectivo acuerdo del Senado, produjo incluso promociones (v. Bergalli 1986).

La situación que se acaba de describir confirma una tradición que se ha venido verificando en Argentina cada vez que reconstituidas las instituciones democráticas y la plena vigencia de la Constitución, tanto el Poder Ejecutivo como el Legislativo renuncian a las ocasiones históricas para proceder a una clara y terminante depuración del cuerpo judicial que es absolutamente admitida por el sistema constitucional. La continuidad de una clase judicial que visiblemente ha estado dependiendo de las contingencias y presiones de los distintos regímenes de facto traduce una de las más relevantes frustraciones en la historia institucional de Argentina, habiendo dado lugar esa falta de independencia exterior y el virtual sometimiento de los magistrados al poder político a lo que con propiedad también se denomina como cuestión judicial (cfr. Bergalli 1984 a).

Este aspecto previo que he querido destacar, aparte de constituir un factor decisivo en la formación material de la ideología «del olvido» a través de prácticas jurídicas concretas, ha servido también para condicionar una de las dos fases en que se ha articulado la elaboración del discurso jurídico específico para encarar en Argentina la aludida cuestión militar.

La endeblez o sesgo erróneo adoptado por la estrategia oficial frente a la cuestión militar, como dije antes, se manifestó a poco de iniciado el gobierno democrático. En efecto, la casi ingenua creencia que el Consejo Supremo de las Fuerzas Armadas (C. S. FF. AA.), máximo órgano 
judicial castrense, iba a profundizar la investigación de los hechos atribuidos a los Comandantes de las tres primeras Juntas Militares cuyos procesamientos había dispuesto el Poder Ejecutivo en la forma indicada y a sus subordinados, ejecutores de las órdenes de exterminio, si bien se apoyaba en una reforma del Código de Justicia Militar (ley 23.049) que había sido alcanzada con un amplio quorum legislativo, por la cual se indicaban las alternativas a seguir en caso de dilación por la jurisdicción castrense, lo cierto es que puso de manifiesto la endeblez señalada. Puesto que los jueces militares no únicamente dilataron los procesos pertinentes, sino que, cuando fueron requeridos por la Justicia Federal para que dieran cumplimiento a sus cometidos e informaran sobre el estado de las correspondientes causas, primero adoptaron una actitud reticente y después renunciaron a sus cargos (cfr. Bergalli 1984 b; EL PAÍS, 15-XI-84), claramente quedó manifestada la negativa de la clase militar a aceptar responsabilidades ni a admitir que fuera el poder político, legítimamente constituido, el que las determinara.

En este punto nace el protagonismo, con amplia repercusión internacional, asumido por el Fiscal y los magistrados integrantes de la Cámara Federal de Apelaciones de la Capital Federal, por y ante quienes se realizó el célebre proceso contra los nueve Comandantes que posteriormente derivó en la sentencia de 9 de diciembre de 1985.

Esta sentencia acarreó dos condenas a reclusión perpetua (Tnte. Gral. Videla y Alte. Massera), unas penas de privación de libertad menores (Alte. Lambruschini, Brigadier Gral. Agosti y Tnte. Gral. Viola) y otras absoluciones (Brigadieres Grals. Graffigna y Lami Dozo, Tnte. Gral. Galtieri y Alte. Anaya). Pero, entre todas sus decisiones afirmó dos tesis que, más allá de su rara ambigüedad, traducen el latente pasado profesional de los magistrados que firmaron la sentencia, todos ellos jueces nombrados o promovidos durante la dictadura militar y ahora confirmados por el gobierno democrático.

La primera de esa tesis es la que emerge del famoso punto 30 de la sentencia mediante el cual se dejó planteado el tema de la obediencia debida, pues a través de esta tesis se abrió la posibilidad de proseguir o iniciar denuncias contra aquellos oficiales superiores que actuaron en «la lucha contra la subversión» (sic) y de «todos aquellos que tuvieron responsabilidad operativa en las acciones» (sic). La otra tesis es aquella por la cual la sentencia privilegió las responsabilidades concretas de cada Comandante y de cada Fuerza (siempre sostenida por las defensas de los Jefes Militares procesados), afirmando, asimismo, que durante la represión existió un estado de guerra revolucionaria, reconocimiento este que los militares siempre habían demandado para explicar de este modo sus actividades represivas.

La oscuridad que la sentencia aportó al afirmar esas dos tesis dio lugar a una situación que se caracterizó, por un lado, por el deseo de interpretar el lenguaje de los jueces, pleno de ambigüedades, con el objeto de favorecer la condición de futuros imputados o la contraria de seguir adelante con las investigaciones respecto de los excesos cometidos durante la represión. Por el otro lado, se buscaba esclarecer la posición 
del gobierno constitucional en su propia estrategia frente a la cuestión militar. Pero nada de esto fue logrado; en cambio, creció una situación conflictiva entre el Poder Ejecutivo y los magistrados judiciales, cuadro este que favoreció la elaboración de hipótesis conducentes a justificar o excluir las responsabilidades de los integrantes de las FF. AA. en las graves violaciones de derechos humanos y delitos comunes.

En efecto, no pasó mucho tiempo después de pronunciarse la sentencia de 9 de diciembre de 1985 cuando comenzó a hablarse en Argentina acerca de la necesidad de llegar a una solución de cara a los múltiples procesos penales que se iniciaron contra aquellos oficiales -en relación a los cuales han existido abundantes elementos probatorios- que, de una forma u otra, quedaban involucrados en aquella ambigua fórmula de la responsabilidad operativa en las acciones.

Los argumentos que desde entonces se esgrimieron fueron aquellos ligados a lo innecesario y desgastador que podía ser una prolongación del estado de enjuiciamiento permanente de las FF. AA. en su conjunto, pues se alegaba que procesar «en catarata» a muchos de sus miembros suponía un encausamiento de todas las instituciones militares con el consiguiente riesgo que ello acarrearía para la estabilidad política. Además, la otra tesis de la sentencia de la Cámara Federal -aquella que afirmó que la represión desatada durante la época entre 1976 y 1983 fue en verdad la respuesta a un estado de guerra revolucionariadio pie para explicar que en momentos semejantes la lucha antisubversiva puede llevar a concretar excesos.

\section{IV}

La argumentación antes sintetizada -que partió de muy diferentes sectores sociales y políticos pero siempre proclives al poder militar- preparó el terreno para que lo que he denominado como discurso jurídico oficial se fuera allanando a la ideología «del olvido», haciendo el gobierno democrático importantes concesiones a las presiones que venía recibiendo.

A) Una primera concesión consistió en el proyecto de ley que disponía la extinción de las acciones penales -vencido determinado lapso, aunque en todo caso excepcionalmente mucho más breve a los previstos en el régimen ordinario del Código Penal- contra miembros de las FF. AA., de seguridad, policiales y penitenciarias, imputados por delitos cometidos en el marco de la represión contra la subversión. Se trata de la denominada ley «de punto final», la cual, de verdad, tanto desde el punto de vista ético como desde el estricto jurídico-penal y procesal o resiste el análisis, pese a los esfuerzos que se hayan hecho en sentido contrario (cfr. Malamud Goti/Entelman 1987).

En efecto, del número de cuatro argumentos del primer carácter que se alegaron en el mensaje del Poder Ejecutivo elevando al Congreso el proyecto de ley (v. LA NACIÓN-internac. 9-XII-86) pueden aquí extraerse sólo dos que, por su fragilidad, contrastan con la base ética atribuida 
a esa ley, sobre todo si se les analiza desde los fines de la pena como lo hacen los juristas que intentan justificar el castigo de los militares violadores de derechos humanos, aunque encontrando el modo de limitar los procesos penales. Tales argumentos son:

1) «prevenir que el espíritu de justicia, deformado por la pasión, fuera el marco que hiciera posible una campaña de venganza, punto de partida de una nueva etapa de violencia que la sociedad argentina rechaza» $\mathrm{y}$,

2) «lograr que ello se desarrollare en el menor tiempo posible, para aventar rápidamente el estado de sospecha indiscriminada que se proyectaba sobre las FF. AA. como instituciones y para permitir que la totalidad de los argentinos clausuraren una de las etapas más oscuras de la historia nacional, de modo que, reconciliados sobre la base de la verdad y la justicia, pudiéramos conseguir juntos la urgente tarea de reconstruir la Nación».

Pues bien, más allá de reconocer, por una parte, la dificultad que supone establecer parámetros de justicia en asuntos tan repulsivos como lo fueron las crueles violaciones de derechos humanos atribuidos al personal militar, resulta paradójico, en cambio, sustentar un espíritu de justicia como objetivo del gobierno democrático cuando se alega que la principal justificación del castigo en el caso resulta de lo que se denomina la prevención general indirecta (así Malamud Goti/Entelman op. cit.). Si se tienen en cuenta las tesis centrales del retribucionismo y del utilitarismo penal -originarias en la narración histórica ateniense, reapareciendo en los intentos de compromiso entre una y otra y reproduciéndose más tarde en boca de recientes defensores de una u otra corriente (todo lo que ha demostrado en Argentina Enrique E. Mari, cfr. 1982, 189 y ss.)- puede concluirse aquí muy sintéticamente, diciendo que el retribucionismo justifica el castigo en razones de justicia y el utilitarismo apela a las consecuencias valiosas del castigo para explicar su necesidad. Puesto que en la teoría de la pena, justificación $=$ fundamentos de la reacción (y de aquí parten las teorías absolutas) y consecuencias = fines (que son explicados mediante las teorías relativas), es evidente que resulta por lo menos contradictorio justificar el castigo con una de sus consecuencias.

Por otra parte, por más que se aleguen urgentes motivos de reconstrucción nacional (lo que efectivamente hay que buscar), para lo cual sería necesario clausurar una de las etapas más oscuras de la vida nacional (según el mensaje que remite el proyecto de ley al Congreso argentino $)^{1}$, no puede aceptarse la fijación de un régimen excepcional de caducidad de las acciones penales respecto de militares y miembros de otras fuerzas que cometieron gravísimos delitos tipificados en el Código Penal con un supuesto propósito de reprimir el terrorismo, para disipar «el estado de sospecha indiscriminada que se proyectaba sobre las FF. AA. como instituciones».

\footnotetext{
${ }^{1}$ Pero, ¿es posible creer que alguien pueda afirmar sinceramente que una ley tal es capaz de conllevar a ese objetivo de reconstrucción nacional y de reconciliación, sobre la base de la verdad, a toda 1a sociedad argentina y en especial a quienes más han sufrido y sufren los efectos de aquel horror?
} 
Es verdad que, frente a la existencia de un régimen común de prescripción que determina una escala en términos de transcurso del tiempo, según las penas previstas para cada delito, para hacer decaer la facultad punitiva del Estado (Libro I, Título X, arts. 59-70, Código Penal), resulta por lo menos irritante constituir un régimen de privilegio como el instaurado. Con ello, desde un primer momento, se viola el principio de igualdad ante la ley que la Constitución argentina establece en su art. 16, tal como todas las cartas magnas de los países de nuestra civilización ${ }^{2}$.

La discusión que aún se mantiene en doctrina penal acerca de la prescripción, se refiere particularmente a la naturaleza de esta categoría jurídica. Las distintas posiciones varían en otorgarle un carácter de causa de exclusión de la punibilidad, otra de impedimento a la acción persecutoria (en el proceso) o bien mixto de ambos. Según la primera, se le atribuye una naturaleza material; según la segunda, otra formal-procesal (cfr. Zaffaroni 1983 V, 23-29). Sin embargo, desde que este instituto está previsto en el propio Código Penal argentino, restringiendo o limitando la coerción penal, la discusión parece haber sido superada en doctrina nacional. Mas, lo que realmente interesa aquí destacar es lo relativo al fundamento que casi unánimemente se le atribuye a la categoría de la prescripción del delito (o prescripción de la pena, en derecho argentino), cual es el que se vincula con la necesidad de pena. De tal manera, la prescripción del delito supone una decisión de carácter político-criminal que se relaciona con las exigencias que la sociedad formula para olvidar y considerar inútil o ineficaz la persecución, apoyándose en una consideración global del delito y del sujeto responsable de éste (cfr. Bustos Ramírez 1984, 460). Este tipo de análisis es el que precisamente justifica la imprescriptibilidad de ciertos delitos contra la humanidad y crímenes de guerra.

En consecuencia, es asombroso que el pronunciamiento legislativo argentino -que por su carácter involucra a toda la clase política- haya decidido como necesario de olvido conductas que han lesionado sentimientos colectivos, profundos y precisos, poniendo en crisis la propia cohesión social, acometiendo contra la solidaridad mecánica de la sociedad argentina y su conciencia que se suponen expresadas en el derecho penal (Durhkeim). Al violentarse una de las categorías de este último y especial instrumento de control social, dando por supuestamente innecesaria la persecución de delitos y de sus autores -que han atacado sentimientos de tanta entidad como el respeto a la vida humana, a la integridad física y moral de los individuos, en razón de una situación

\footnotetext{
${ }^{2}$ Vale la pena recordar aquí el reproche que un psicólogo argentino dirigió a la ley de «punto final», cuando dijo: «se encubre con una pretendida moralidad (no pone bajo sospecha a todo un estamento por más tiempo) lo que resulta en el fondo una actitud carente de ética; miedo al más fuerte (FF. AA.) en menoscabo del más débil, pues al fin y al cabo, ¿qué son unos cuantos miles de personas que claman justicia por sus familiares desaparecidos y cuyas armas son únicamente el dolor y la reivindicación de la memoria y dignidad de los suyos?» (v. Vilchez Martín 1987).
} 
coyuntural- ha quedado al descubierto un estado de anomia difícil de subsanar.

No obstante el paso dado por el gobierno democrático, cediendo a las presiones y encausando erróneamente la estrategia oficial respecto a la cuestión militar, la soberbia del estamento castrense volvió a hacerse manifiesta en la medida que se ha venido readmitiendo su poder político. Reiteradas y expresivas manifestaciones pronunciadas por los propios jefes militares nombrados por el gobierno democrático, resaltaron la voluntad de la clase militar en lograr la plena reivindicación de la represión ejercida durante la década «bárbara». La legitimación de la denominada «guerra sucia», no fue considerada suficiente con la ya sancionada ley «de punto final» (n. ${ }^{\circ}$ 23.492) y los argentinos tuvieron que apurar nuevas exigencias militares. Mientras tanto, el 30 de diciembre de 1986 la Corte Suprema de Justicia de la Nación confirmó la sentencia de la Cámara Federal manteniendo algunas de las condenas, reduciendo otras y dejando entrever que entre sus jueces existió una controversia acerca del reconocimiento de la categoría de autor para los responsables de las violaciones a los derechos humanos durante la represión militar, la cual, de haber triunfado la tesis de la minoría de esos magistrados, podría haber influido contra la ideología «del olvido» que ya había permeado el discurso jurídico. Nuevos y posteriores conflictos entre Poder Ejecutivo, Consejo Supremo de las FF. AA. y Justicia Federal pusieron en evidencia la clara debilidad del gobierno democrático y la irrefrenable búsqueda de la clase militar para obtener el total reconocimiento de sus pretensiones.

Todas estas alternativas (de las que me he ocupado ampliamente en forma reciente, cfr. Bergalli 1987) completaron el cuadro previo en el que se enmarcan la predisposición de gran parte de la clase política con representación en el arco parlamentario para allanarse a las exigencias como, asimismo, el evidente desconocimiento por el poder militar de las decisiones de la jurisdicción civil. De esta manera fue como se llegó a los temibles momentos provocados por la insubordinación de amplios sectores del Ejército durante los días de la Semana Santa, con vasta repercusión internacional. Esa actitud militar casi generalizada tuvo el claro propósito de torcer decisiones ya asumidas por los poderes constitucionales (con lo cual se habrían infringido alguno de los tipos penales previstos por la ley 23.077 de «Protección del orden constitucional y de la vida democrática) y no se habría incurrido en el amotinamiento (figura penal de menor entidad y que cae bajo la jurisdicción castrense) de que habló el mismo Presidente Alfonsín cuando el domingo de Ramos aludió a la conducta de los oficiales insubordinados en Campo de Mayo. Este último detalle puso de relieve la inferioridad en que estaban las instituciones democráticas frente a la intacta soberbia de la clase militar.

Cabe destacar con énfasis el papel que inéditamente cumplió, no obstante lo ocurrido, de forma inédita el pueblo argentino. No únicamente en la Plaza de Mayo de Buenos Aires, sino ante los propios destacamentos militares, en muchas capitales del interior y en localidades alejadas de la Capital manifestó su repudio por el comportamiento castrense, con lo que se marcó el aislamiento de la sociedad civil tanto de las FF. AA. 
-que actúan como cuerpo separado del Estado- como de la propia clase política lo que, ciertamente, no deja de ser otro preocupante signo para la propia vida democrática. Por lo demás, la aparente clausura de esa crisis, sellada con la conducta del Presidente Alfonsín, trasladándose valerosamente hasta el reducto de los sediciosos para parlamentar con ellos, dejó al descubierto la desventaja del gobierno constitucional; pero, al mismo tiempo, señaló que en Argentina no parece posible realizar el tránsito a la democracia sin custodios mientras no se proceda a una profunda depuración de las FF. AA. y a encontrarles una definitiva ubicación para marginarlas del esquema de poder político.

$B$ ) La segunda y más reciente concesión que el gobierno democrático acaba de hacer en esta carrera de pérdida de iniciativa en la cuestión militar, consiste en el proyecto -luego modificado ante urgentes presiones recibidas- y posterior sanción de una ley mediante la que se introdujo un régimen especial para la aplicación -en los procesos penales en que se encuentren imputados integrantes de las FF. AA., policiales, de seguridad y penitenciariasdel principio de la obediencia debida.

El inmediato comportamiento del Poder Ejecutivo, a seguido de los sucesos de Semana Santa, requiriendo sugerencias para modificar la aplicación tradicional del principio de la obediencia debida -que cuenta con una acendrada tradición en la dogmática penal nacional e internacional- y un dictamen del Procurador General de la Nación (Fiscal Gral.), preanunciaron la clara voluntad del gobierno constitucional -apoyada por un amplio sector de las fuerzas políticas parlamentarias y del propio Partido Radical en el gobierno (aunque con escasas pero marcadas disidencias, siempre refrendadas por los organismos de defensa de los derechos humanos)- para encontrar todavía un marco legal más amplio que permitiera excluir de responsabilidad criminal ahora a la mayor parte de los directos ejecutores militares de la «guerra sucia». Estos, por lo demás, fueron quienes tomaron la iniciativa en la insubordinación casi generalizada de la Semana Santa.

Puesto que las distintas propuestas para una ley parecieron no satisfacer al Presidente Alfonsín, éste asumió personalmente la iniciativa legislativa formulada por el Secretario de Estado de Justicia ante las constantes manifestaciones del poder militar. Así se envió un proyecto para tratar específicamente los casos de «quienes, a la fecha de comisión del hecho revistaban como oficiales, jefes, oficiales subalternos, suboficiales y personal de tropa de las FF. AA., de seguridad, policiales y penitenciarias» respecto de los cuales «se presume, sin admitir prueba en contrario» que «no son punibles por los delitos a que se refiere el art. 10, punto 1 de la ley 23.049 (operaciones emprendidas con el motivo alegado de reprimir el terrorismo) por haber obrado en virtud de obediencia debida. En tales casos se considerará de pleno derecho que las personas mencionadas obraron en estado de coerción bajo subordinación a la autoridad del superior y en cumplimiento de órdenes, sin facultad o posibilidad de inspección, oposición o resistencia en cuanto a su oportunidad y legitimidad». El art. 2. ${ }^{\circ}$ del Proyecto excluye de esa presunción a quienes estén acusados por los delitos de violación, sustracción y ocultación 
de menores o sustitución de su estado civil y apropiación extorsiva de inmuebles (v. LA NACIÓN-internac. 18-V-87).

Es vastamente conocido el tratamiento que tuvo este proyecto en sede parlamentaria, habiendo nacido en el Senado las dificultades de aceptarlo tal como estaba por representantes de partidos del interior del país, de la derecha y del sector autodenominado «ortodoxo» del peronismo, quienes claramente acicateados por las exigencias públicas de los más elevados jefes militares en activo, propiciaban que los beneficios de la obediencia debida alcanzaran también a los cargos superiores de las FF. AA. El Presidente Alfonsín, que se negaba a modificar su propuesta, dio, a la postre e imprevistamente, la orden partidista a los senadores radicales de aceptar una modificación al proyecto de ley. De este modo, ostensiblemente arrinconada la clase política, la ley quedó sancionada con el siguiente agregado: «La misma presunción (obediencia debida) será aplicada a los oficiales superiores que no hubieran revistado como comandante en jefe, jefe de subzona o jefe de fuerza de seguridad, policial o penitenciaria si no se resuelve judicialmente antes de los 30 días de la promulgación de esta ley que tuvieron capacidad decisoria o participación en la elaboración de órdenes».

\section{Conclusión}

Este es el más reciente pero quizá no el último de los avances realizados por el poder militar sobre el sistema y las instituciones democráticas en Argentina. Lamentablemente, el decurso de la situación política en los casi cuatro años de vida del régimen constitucional de gobierno no permiten prever un fortalecimiento del mismo pero lo que es quizá tan o más grave aún, lo constituye la formulación de una nueva etapa en la construcción de ese discurso jurídico particular dirigido a la cancelación de la memoria colectiva en relación a la cuestión militar en el país. Excede el límite de lo tolerable para un lógico juicio jurídico la desnaturalización de la causa de justificación o exculpación de delitos aberrantes por un supuesto deber de obediencia coercitivo que habría impedido a los subordinados y hasta a los propios jefes con responsabilidad operativa examinar el contenido de la orden de matar, torturar o hacer desaparecer durante la llamada «guerra sucia». Pero aun todavía es más fuerte el rechazo de esta ideología «del olvido» impuesta mediante el retorcimiento de categorías jurídico-penales cuando se comprueba que la impunidad sancionada para los crímenes más graves desborda ya cualquier explicación política al negar la responsabilidad de los autores materiales; constituye una verdadera afrenta para las víctimas de la brutal represión; desprecia el largo camino transitado en Argentina para la protección de los derechos humanos; pone en crisis al propio sistema democrático y debilita totalmente la legitimidad del mensaje ético con que se postuló y se inició el gobierno de Alfonsín.

Parece imposible superar la década «bárbara» proponiendo el olvido y la cancelación de lo ocurrido mediante formas ocultadoras o encubridoras 
del discurso jurídico. Ello constituye una tentativa que va precisamente contra los deseos de reconstrucción nacional, proyecto que debe basare precisamente en que cada grupo asuma crítica y reflexivamente las repercusiones de sus comportamientos sobre todo el cuerpo social. Proceder de otra forma supone una limitación del conocimiento y el análisis del pasado de los pueblos lo que para cualquier sociedad que pretende identificarse y perpetuarse como tal es «el elemento fundamental de su unidad y de su personalidad, mientras que la transmisión de este capital intelectual es la condición necesaria para la supervivencia material y social» (v. Leroi-Gaurhan 1977, vol. II, 304).

Julio de 1987 


\section{BIBLIOGRAFÍA}

BERGALLI, R. (1981), Proyectos hegemónicos y Estado autoritario en la Argentina, en: «Sistema - Revista de Ciencias Sociales», 41, mayo, Madrid 17-29.

BERGALLI, R. (1984 a), Estado democrático y cuestión judicial (Vias para alcanzar una auténtica y democrática independencia judicial), Depalma, Buenos Aires.

BERGALLI, R. (1984 b), El esquema político-criminal de la democracia argentina, en: «Revista del CIDOB - Afers Internacionals», tardor-hivern, n. ${ }^{\circ}$ 5, Barcelona 101-121.

BERGALLI, R. (1986), El poder y los jueces latinoamericanos: los modelos argentino y colombiano, en: «Revista del CIDOB - Afers Internacionals», primavera, n. ${ }^{\circ} 8$, Barcelona 49-61.

BERGALLI, R. (1987), Memoria colectiva y derechos humanos, en: «Teoría del derecho y derechos humanos en Latinoamérica», Anales de la Cátedra Francisco Suárez, Departamento de Filosofia del Derecho-Falcultad del Derecho, Universidad de Granada.

BUSTOS RAMÍREZ, J. (1984), Manual de derecho penal español - Parte General, Ariel Derecho, Barcelona.

DURKHEIM, E. (1982), La división del trabajo social, (trad. C. G. Posada), estudio preliminar: Luis R. Zúñiga, Akal/Universitaria- Serie sociología 39, Madrid.

EL PAÍS (1984), Nuevas dimisiones en la cúpula de la justicia militar argentina, por C. Ares (Buenos Aires), Madrid-Barcelona, 15 noviembre.

ENTELMAN, R. (1982), Introducción a: P. Legendre y otros, «El discurso jurídico Perspectiva psicoanalítica y otros abordajes epistemológicos», Hachette, Buenos Aires, 9-20.

FOUCAULT, M. (1983), El orden del discurso, (trad. A. González Troyano), Cuadernos Marginales 36 -Tusquets editores, 3. ${ }^{\text {a }}$ ed., Barcelona.

LA NACIÓN (1986), Se envía al Congreso el proyecto de punto final, ed. internac. vía aérea n. ${ }^{\circ} 1.368,8$ diciembre, $1-5$.

LA NACIÓN (1987), El Presidente explicó al país el proyecto de obediencia debida, ed. internac. -vía aérea, n. $^{\circ} 1.391,18$ mayo, 1.

LEROI-GOURHAN, A. (1977), Il gesto e la parola, (trad. del francés), Einaudi, Torino, 2 vols. (I, 254; II, 482).

MALAMUD GOTI, J. / ENTELMAN, R. (1987), La justificación del castigo, los juicios a militares argentinos, el llamado «punto final» y sus consecuencias políticas, en: «Teoría del derecho y derechos humanos en Latinoamérica», op. cit.

ROUQUIÉ, A. (1983), Poder militar y sociedad política en la Argentina, vol. I: Hasta 1943, (trad. A. Iglesias Echegaray), Emecé editores, Buenos Aires.

VILCHEZ MARÍN, L. (1987), No al punto final, en: EL PAÍS, Madrid-Barcelona, 21. Febrero, 4/Internacional.

ZAFFARONI, E. R. (1983), Tratado de Derecho Penal-Parte General, T. V, Ediar, Buenos Aires. 


\section{ADDENDA}

Tal como se dijo en la Conclusión del precedente trabajo, era de prever que las alternativas impelentes de la última de las concesiones efectuadas por la clase política en su conjunto -la obtención de una ley, llamada de «obediencia debida», que ahora lleva el $\mathrm{n}$. 23.521- «era el más reciente pero quizá no el último de los avances realizados por el poder militar sobre el sistema y las instituciones democráticas en Argentina».

Esa reflexión no pudo ser más previsora. En efecto, el trabajo fue concluido en julio de 1987. Mientras, en los meses subsiguientes se han venido produciendo decisiones jurisdiccionales y eventos militares que, en un análisis como el anterior, al efectuarse la publicación de este texto, no pueden quedar al menos sin exposición para así poder redundar y confirmar la tesis que se ha sostenido, cual es: la de que la construcción de un discurso jurídico específico, elaborado por juristas y jueces en torno a la cuestión militar, ha sufrido un condicionamiento tal como para dotarlo con una ideología «del olvido».

De tal modo, debe destacarse, en primer lugar, la resolución de la Corte Suprema de Justicia en relación con la inhibidora de competencia, planteada por la Justicia Militar al Juez Federal de San Isidro (Prov. de Buenos Aires), quien abrió el respectivo sumario contra el entonces Tte. Cnel. Aldo Rico por los sucesos por él protagonizados durante los días de la Semana Santa de 1987, en la Escuela de Infantería de Campo de Mayo, a los que se alude en el trabajo anterior. En esa resolución, adoptada por mayoría con apoyo en el dictamen del Procurador General de la Nación, la Corte Suprema (competencia n. ${ }^{\circ}$ 322, Libro XXI) decidió en 17 de diciembre de 1987 que la competencia para conocer en ese sumario correspondía a los tribunales militares pues el delito a investigar era el de motín (art. 108, Cód. de Justicia Militar) y no el de rebelión (previsto en el art. 226 del Cód. Penal), o sea que correspondía conocer hechos de naturaleza castrense cometidos por personas sujetas a deberes militares. De esta manera, por vía jurisdiccional, se confirmaba la decisión política ya asumida por el propio Presidente Alfonsín, cuando había calificado los sucesos encabezados por Rico y sus secuaces como propios de amotinados.

Sin embargo, la declaración de la Corte Suprema no fue una decisión unánime de sus cinco ministros integrantes. El voto disidente de Jorge A. Bacqué, puntualizó muy circunstanciadamente todos los elementos que, habiendo sido dejados de lado por el Procurador de la Nación, comprobaban la manifiesta voluntad de Rico y compañeros por arrancar a los poderes públicos la aprobación de una ley de amnistía para todos los acusados de haber llevado a cabo la denominada "guerra sucia»; es decir, habían consumado una adecuación típica de sus comportamientos a las figuras penales de la ley 23.077 de «Protección del orden constitucional 
y de la vida democrática». Por todo ello, a juicio de cualquier lector atento de esa resolución de la Corte, quedará muy evidente la sesgada actitud del Procurador y de los ministros del alto Tribunal que votaron a favor de la competencia castrense.

Los hechos que posteriormente siguió protagonizando Aldo Rico, fugándose mientras gozaba un régimen de prisión preventiva atenuada otorgado por la justicia militar y alzándose en armas en Monte Caseros (Prov. de Corrientes) durante la tercera semana de enero pasado, pusieron en vilo a las instituciones democráticas y ratificaron lo negativo de la comentada decisión de la Corte Suprema.

Casi contemporáneamente, este Tribunal supremo se expidió por mayoría (en 25 de febrero) con el voto en contra otra vez del ministro Jorge A. Bacqué, en aplicación de la llamada ley de «punto final» o de prescripción privilegiada 23.492, absolviendo sin entrar a analizar el fondo de la imputación al ascendido por el Poder Ejecutivo capitán de corbeta Alfredo Astiz, símbolo de la represión en Argentina durante los siete años de dictadura militar, a quien se acusaba de estar implicado en la desaparición y posterior muerte de la joven Dagmar Hagelin de origen sueco.

Una síntesis que resuma las consecuencias jurídicas y políticas de las decisiones jurisdiccionales y los hechos militares apuntados, no puede ser otra que, al mismo tiempo de atribuirles una contribución a la inestabilidad institucional, les reproche -lo que es más grave todavía- poner en cuestión la legitimidad del sistema democrático por haber debilitado el substrato ético que particularmente le dio nacimiento en la República Argentina (cfr. E. Garzón Valdés, La democracia argentina actual: problemas ético-políticos de la transición, en: «Sistema-Revista de Ciencias Sociales», 82, enero 1988, págs. 85-99).

Marzo de 1988. 